\title{
Using Internet-based nominal group technique meetings to identify provider strategies for increasing diaphragm use
}

\author{
Andrzej Kulczycki, Richard M Shewchuk
}

\begin{abstract}
Background and methodology The diaphragm, once the most commonly used female contraceptive method, is being re-evaluated for prevention against some sexually transmitted infections (STIs), including HIV. However, provider views about this prescription-based method are poorly understood. Using expert panels, this study aimed to identify facilitative strategies to increase diaphragm use. The nominal group technique (NGT) was employed using a novel web-based interface to systematically elicit and prioritise responses to a specific question about what can be done to encourage providers to recommend diaphragm use. Two NGT sessions were convened with 15 geographically dispersed panellists who had extensive knowledge and experience with the diaphragm. Participants were identified using purposeful and snowball sampling.
\end{abstract}

Results Panel 1 identified 22 strategies for encouraging providers to recommend diaphragm use, with seven perceived as relatively more important $(67 \%$ of the total available votes). Panel 2 identified 31 strategies, nine of which accounted for $77 \%$ of the votes. Both sessions highlighted that to make the diaphragm a more plausible option, educational materials and tools are needed to better inform providers and patients about the method and its specific advantages.

Conclusions The enhanced, Internet-based NGT offers the family planning and reproductive health care field a powerful and inexpensive tool for systematically collecting and analysing expert opinion. Results are being used to develop a questionnaire to further examine strategies that may help promote diaphragm use and to refine ideas for intervention design. This will facilitate method reintroduction, if the diaphragm is proven effective against STIs/HIV, especially when used with a microbicide.

Keywords barrier method, diaphragm, nominal group technique, qualitative research, STI prevention

J Fam Plann Reprod Health Care 2008; 34(4): 227-231

(Accepted 6 February 2008)

\section{Introduction}

Writing recently in this journal, van Teijlingen et al. succinctly described the availability of the Delphi method and the nominal group technique (NGT) for eliciting expert opinion in a systematic way. ${ }^{1}$ They also noted four or five stages involved in the NGT process and the importance of identifying an appropriate panel of key informants. Both participatory techniques have been used for several decades in health care research. ${ }^{2,3}$ However, only a few applications of the NGT have been described in the reproductive health field, 4,5 offering little guidance on methodological issues. This study seeks to remedy these twin information deficits. Moreover, it extends the basic NGT technique by describing implementation of the nominal group process through a web-based interface. This enhanced approach is adopted to identify facilitative strategies to increase provider willingness to recommend the diaphragm, a reusable, female-controlled barrier contraceptive that is attracting renewed attention for its potential to prevent some sexually transmitted infections (STIs), including HIV. The article also aims to facilitate future applications of the NGT technique, a versatile but under-utilised method by reproductive health researchers, administrators and policymakers.

Department of Maternal and Child Health, School of Public Health, University of Alabama at Birmingham, Birmingham, AL, USA

Andrzej Kulczycki, PhD, Associate Professor

Department of Health Services Administration, School of Health Related Professions, University of Alabama at Birmingham, Birmingham, AL, USA

Richard M Shewchuk, PhD, Professor

Correspondence to: Dr Andrzej Kulczycki, Department of Maternal and Child Heath, University of Alabama at Birmingham (UAB), 320 Ryals Public Health Building, 1665 University Boulevard, Birmingham, AL 35294-0022, USA

E-mail: andrzej@uab.edu

\section{Key message points}

- The nominal group technique (NGT) was employed using a novel web-based interface to systematically elicit and prioritise two panels' responses to a question about strategies for promoting diaphragm use.

- Both sets of panellists highlighted the need for multimodal educational and counselling strategies that providers could use when discussing the diaphragm with patients.

- Effective NGT implementation requires careful consideration of panel composition and how the issue being addressed is presented to the group.

\section{Rationale for NGTs}

Both the NGT and Delphi technique provide anonymity, iteration, controlled feedback and statistical group response.1,2,6 Delphi surveys have been used more broadly in international health ${ }^{7-9}$ and are typically administered through mail questionnaires, with some recently held by Internet. ${ }^{10}$ Despite considerable strengths, the Delphi method usually involves at least three meeting rounds to reach consensus. ${ }^{11,12}$ This is time-consuming and makes it harder to sustain high response rates. ${ }^{13}$ Also with successive rounds, minority views may be lost as the number of categories is reduced in order to derive a consensus. ${ }^{12,14}$ The method does not build on the benefits of having an assembled group synchronously involved in the process. Pitfalls in using the Delphi technique have been described elsewhere. ${ }^{3}$

We contend that use of the nominal group process, with the refinements described here, may ameliorate many of these shortfalls. Although it is more expedient than the Delphi technique, the NGT process has traditionally required face-to-face meetings. This limits participation to a circumscribed geographic area. Use of the Internet and conventional conference calling can help us overcome this limitation. It also preserves the benefits of having an 
assembled group address a problem. Thus, a 'virtual NGT' can pull in experts from diverse geographical areas via the Internet and can effectively be conducted in person. We believe such an approach is more efficient and parsimonious than either the Delphi or conventional NGT methods.

NGTs can be used for problem exploration, 2,5 as a ranking exercise, ${ }^{15}$ or as a consensus-building strategy. ${ }^{16}$ This study applied the nominal group process to generate ideas and to rank responses. Our purpose was not to achieve consensus, but to identify issues germane to our future research through a structured, systematic approach.

NGT sessions typically involve the following steps: (1) silent, written generation of responses to a specific question; (2) 'round-robin' recording of ideas; (3) serial discussion for clarification; and (4) prioritisation of responses. The highly structured format of NGT meetings promotes equal involvement of participants and controls extraneous and evaluative discussion that frequently occurs in group sessions when controversial issues are addressed or when there are real or perceived power differentials among participants. ${ }^{17,18}$ By minimising sources of process loss, NGT meetings, relative to unstructured focus group meetings, tend to elicit a greater volume of information regarding some specified issue. ${ }^{2,19,20}$ The NGT also provides concise recorded documentation summarising participants' responses to a specific question which makes audiotape recording and transcription unnecessary. The objective recorded summary of the ordinal data generated by this process is assumed to provide a valid and easily interpretable reflection of the implicit views held by a group. This is because the NGT tends to promote even rates of participation and equally weights the input from all group members. Important insights are obtained when using the NGT, if a carefully articulated question based on clear understanding of specified information needs can be addressed by a representative group of knowledgeable informants.

\section{Re-thinking the diaphragm for disease prevention}

Our application relates to the growing interest in the diaphragm's potential preventive role against HIV and other STIs. The diaphragm is one of the oldest contraceptive devices. It is safe, reasonably effective and remains available, notwithstanding falling prevalence rates. It is also a female-controlled technology recently touted as a promising new intervention for STI/HIV prevention. ${ }^{21}$ Both epidemiological and biological evidence suggest the diaphragm may provide protection against cervical STIs ${ }^{22-24}$ and even HIV. ${ }^{25}$ The diaphragm may additionally serve as a service delivery vehicle for a microbicide when this option becomes available for STI/HIV prevention. ${ }^{21,26,27}$

A recent trial found no difference in infection rates between women given condoms alone and those assigned the diaphragm, lubricant gel and condoms. ${ }^{28}$ The study design included an important confound, however, because it did not evaluate the diaphragm with a microbicide. Furthermore, the lack of adherence to all three products in the treatment arm may have obscured partial efficacy of the diaphragm and renders study interpretation difficult. Currently, microbicide development is receiving much attention with four ongoing Phase III clinical trials of candidate products. ${ }^{27}$ If a combination 'diaphragm plus microbicide' approach is found to work, as seems plausible, the 're-packaging' of the diaphragm for disease prevention and dual protection may mirror the way condoms have found another use over the last quarter century. However, very little is known about how providers view the diaphragm, a prescription-based method currently recommended only for contraception. This study, therefore, aimed to identify what factors providers think may influence willingness to recommend and use the diaphragm as a viable barrier contraceptive.

\section{Methods}

\section{Study design and formulation of NGT question}

We first conducted a literature review that revealed only a few published provider-based studies on the diaphragm 29,30 and no studies about strategies to promote its use in family planning and reproductive health care. We held in-depth interviews with local providers in Birmingham, Alabama, a city of 1 million people in the southeastern United States. This region has among the highest rates of unintended pregnancy, STIs and HIV/AIDS in the country. ${ }^{31}$ Analyses of data from these in-depth interviews indicated poor knowledge of and limited experience with the diaphragm, and offered few suggestions for advancing its use.

To address our concern more directly, we planned two highly structured meetings, each conducted by telephone for voice communication with participants simultaneously connected by Internet to a website where they recorded their responses. In preparation for these meetings, we developed several candidate questions intended to elicit facilitative strategies for promotion of the diaphragm. Candidate questions were subjected to an informal cognitive interviewing process to evaluate how they were understood and whether they elicited information as intended.32,33 After reviewing question accuracy and clarity, the final question selected for use for the two NGT panel meetings was set as: "What sorts of things/strategies would encourage providers to recommend the diaphragm as a method of birth control?"

\section{Participant selection and recruitment}

Considerable effort was devoted to recruiting experienced and authoritative diaphragm providers. Participants were recruited using purposeful and snowball sampling. Diaphragm manufacturers, family planning officers and other knowledgeable informants were approached for contact information on major diaphragm providers. A call for study participation was posted on the homepage of the website for the Cervical Barriers Advancement Society. Participants had to have extensive experience fitting diaphragms and either a publication on the diaphragm or involvement in a diaphragm research study. To the extent possible, we sought to maximise geographic representation. For both NGT panels, potential participants were contacted by research team members via telephone and/or e-mail to explain the purpose of the inquiry and to check their suitability for the 'virtual panel meeting'. Participants could take part from their home or office so long as they could simultaneously access separate telephone and Internet connections. Two e-mail reminders were sent during the week of each meeting, which participants were told would last 60-75 minutes.

\section{Panel participation}

Two panels of geographically dispersed participants were convened by using a synchronous Internet-based virtual NGT meeting room and basic long-distance teleconference calling. Our virtual NGT system is an application that was built using Microsoft Active Server Pages ${ }^{\mathrm{TM}}$, JavaScript ${ }^{\mathrm{TM}}$ and Microsoft SQL ${ }^{\mathrm{TM}}$. Participants require a web browser, an Internet connection and conference call set-up to use this application, which makes use of a digital subscriber 
line (DSL) Internet connection, standard web browsing, and a telephone-based conference call set-up.

Participants accessed the Internet site and were 'seated' at a virtual table, where they were able to see the names of the other participants. This process was managed by a facilitator trained to conduct such panel meetings. Group members were informed of the meeting's purpose and given a very brief explanation of the structured process and how to navigate within the virtual meeting room. They were then asked to work independently for approximately 5 minutes to develop their own list of concise statements/phrases in response to the set NGT question that was posted to their monitors. Next, each panellist was asked to briefly present their responses to the group in a 'round-robin' format so that everyone had an equal opportunity to contribute. Each response was immediately recorded verbatim by the facilitator on a virtual flip chart posted online to help participants recollect previously nominated responses. Participants in each group were allowed to briefly discuss the nominated responses for the purpose of clarification, not evaluation, to ensure each response was understood.

The final phase of each meeting consisted of a structured prioritisation exercise whereby each panellist selected anonymously from the set of ideas that had been generated the three strategies they considered most important for encouraging providers to recommend diaphragm use. They were then asked to rank order these ideas in terms of their relative importance. Participants were directed to a voting area of the site that listed only their three individually selected ideas. Each panellist had three weighted ballots representing six total votes to use in ranking their selections (three votes assigned to the most important idea, one vote to the least important). Individual voting was conducted anonymously, without discussion. The individual rank orderings were aggregated across participants to derive a group level result presented to the group for comment.

\section{Ethical approval and participant reimbursement}

Approval from the institutional review board of the University of Alabama at Birmingham was secured prior to proceeding with the research. An honorarium of US\$125 was paid to reimburse participants for their time.

\section{Results \\ Panel 1}

The first NGT meeting comprised six panellists, including four nurse practitioners in women's health and two physicians. The nurse practitioners were affiliated with nursing schools or university hospitals, and two had worked on diaphragm-related studies; the physicians included specialists in family medicine and in obstetrics/gynaecology who had each prepared diaphragm instructional material. The meeting elicited 22 ideas for encouraging providers to recommend diaphragm use, primarily focused on developing and transmitting appropriate information to providers and to clinics for onward dissemination to patients.

Of this total, the six panellists endorsed seven strategies as relatively more important than others. These accounted for two-thirds $(67 \%)$ of the 36 total available weighted votes (Table 1). Two ideas were perceived as more important than others: (1) to enhance knowledge that the diaphragm had the potential to protect against STIs (five votes); and (2) to provide women with educational tools such as videos to view in their own home to enhance compliance, information retention and to save clinician time (four votes). Three of the six panellists endorsed these strategies as either the most or second most important approaches, strongly suggesting that providers need information to show that the diaphragm is more useful than is generally perceived.

In addition, five ideas each received three votes to jointly rank as the third most useful strategy, with each of these ideas perceived as most important by one of the six panellists. These were to: (1) enhance information that the diaphragm is one of the safest methods; (2) increase patients' awareness of diaphragm availability; (3) increase research showing diaphragm effectiveness; (4) improve diaphragm efficacy; and (5) get pharmacy representatives to push the diaphragm and make physicians more aware of the method. Again, the need to prepare patient educational materials for providers to use and disseminate was emphasised.

\section{Panel 2}

Nine other panellists participated in the second NGT panel. They comprised eight nurse practitioners and one nursemidwife, all of whom had at least 10 years continuous practice experience with diaphragms and most of whom worked at least part-time in academia. This second NGT meeting elicited 31 ideas for encouraging providers to recommend the diaphragm. From this total, participants endorsed three ideas as being most important: (1) educate providers and patients about the advantages of the diaphragm (eight votes); (2) facilitate detailed conversation among providers, manufacturers and sales representatives about diaphragms (six votes); and (3) market directly to the consumer so that patients will be more aware and ask their providers about the diaphragm (six votes). These three items received $20(37 \%)$ of the 54 total weighted votes (Table 1). In all, six ideas were endorsed by at least two panellists and nine ideas received $77 \%$ of the total weighted votes.

\section{Discussion}

Research needs to address why the diaphragm is now rarely recommended and what can be done to encourage its use should method re-introduction prove warranted. Our panellists indicated that although the diaphragm is largely overlooked by providers and potential users alike, they would be willing to recommend the diaphragm often again if it was shown to have demonstrated efficacy against STIs/HIV in addition to its conventional use for birth control. Panellists further suggested that diaphragm use could be encouraged with appropriately targeted information and communication messages for providers and patients. A strong public health message must be developed that both providers and clients need to hear. These requirements underscore the need for more evidence-based policy on the diaphragm.

In response to these concerns, we note that new studies are pending on the diaphragm's prophylactic efficacy, which may greatly strengthen the scientific rationale for renewed adoption of the method. The provision of educational materials should consider the practicalities of fitting and using the diaphragm, and how providers should deal with these topics. This could be addressed through developing continuing professional development and continuing medical education programmes. Further research is required on the types of training needed and the modalities for such provision. Ultimately, multimodal approaches incorporating educational materials and tools for providers and patients, together with effective counselling strategies, could be employed as facilitative strategies to increase diaphragm use.

This study validates the NGT as a means of collating expert opinion where little evidence exists. The NGT employs a highly structured approach that limits the level 
Table 1 Ranked vote responses for most important strategies to increase provider willingness to recommend the diaphragm: responses from nominal group technique (NGT) panels

\begin{tabular}{|c|c|c|c|c|c|}
\hline $\begin{array}{l}\text { Response } \\
\text { numbera }\end{array}$ & Strategy & $\begin{array}{l}\text { Number of } \\
\text { votes }(n)\end{array}$ & $\begin{array}{l}\text { Individual } \\
\text { weighted }^{\text {votes }}\end{array}$ & $\begin{array}{l}\text { Sum of } \\
\text { votes }\end{array}$ & $\begin{array}{l}\text { Percentage of } \\
\text { total weighted } \\
\text { votes }^{c}(\%)\end{array}$ \\
\hline \multicolumn{6}{|l|}{ NGT Panel 1} \\
\hline 8 & $\begin{array}{l}\text { Enhance knowledge that the diaphragm has } \\
\text { potential to protect against sexually transmitted infections }\end{array}$ & 2 & 3,2 & 5 & 13.9 \\
\hline 14 & $\begin{array}{l}\text { Provide women with educational tools such as videos to } \\
\text { view in their own home to enhance compliance, } \\
\text { information retention and save clinician time }\end{array}$ & 2 & 2,2 & 4 & 11.1 \\
\hline 2 & $\begin{array}{l}\text { Enhance information that the diaphragm is one of the } \\
\text { safest methods }\end{array}$ & 1 & 3 & 3 & 8.3 \\
\hline 7 & $\begin{array}{l}\text { Increase patient awareness of the availability of the } \\
\text { diaphragm }\end{array}$ & 1 & 3 & 3 & 8.3 \\
\hline 12 & $\begin{array}{l}\text { Increase the amount of research showing the } \\
\text { effectiveness of the diaphragm }\end{array}$ & 1 & 3 & 3 & 8.3 \\
\hline 3 & Improve the efficacy of the diaphragm & 1 & 3 & 3 & 8.3 \\
\hline 6 & $\begin{array}{l}\text { Get pharmacy representatives to push the diaphragm } \\
\text { and make physicians more aware of it }\end{array}$ & 1 & 3 & 3 & 8.3 \\
\hline \multicolumn{6}{|l|}{ NGT Panel 2} \\
\hline 22 & $\begin{array}{l}\text { Educate providers and patients on advantages of the } \\
\text { diaphragm }\end{array}$ & 3 & $3,2,3$ & 8 & 15 \\
\hline 1 & $\begin{array}{l}\text { Facilitate some formal means to get stakeholders talking } \\
\text { about diaphragms }\end{array}$ & 3 & $2,1,3$ & 6 & 11 \\
\hline 8 & $\begin{array}{l}\text { Market directly to the consumer so that patients will be } \\
\text { more aware and ask their providers about the diaphragm }\end{array}$ & 2 & 3,3 & 6 & 11 \\
\hline 19 & $\begin{array}{l}\text { Ensure that fitting rings and product are available at all } \\
\text { clinics }\end{array}$ & 2 & 2,3 & 5 & 9 \\
\hline 16 & $\begin{array}{l}\text { Ensure that diaphragm usage is taught to health care } \\
\text { providers and medical faculty so that medical students } \\
\text { are made aware of the diaphragm }\end{array}$ & 3 & $1,2,1$ & 4 & 7 \\
\hline 24 & $\begin{array}{l}\text { Help providers and patients recognise their own biases } \\
\text { against the diaphragm and help them overcome } \\
\text { stereotypical barriers (e.g. messiness) }\end{array}$ & 2 & 1,2 & 3 & 6 \\
\hline 13 & $\begin{array}{l}\text { Facilitate methods of increasing comfort in conversation } \\
\text { among providers by providing evidence-based articles }\end{array}$ & 1 & 3 & 3 & 6 \\
\hline 6 & Give more training to currently practising providers & 1 & 3 & 3 & 6 \\
\hline 7 & $\begin{array}{l}\text { Educate providers about counselling strategies that they } \\
\text { could employ }\end{array}$ & 1 & 3 & 3 & 6 \\
\hline
\end{tabular}

aThis refers to the order in which the responses were generated by participants during the 'round-robin' part of the NGT session. The full list of item responses from the panels is available upon request from the authors.

bEach panel member was allotted three weighted votes and asked to assign one of these weighted votes to each of three strategies selected in terms of their perceived importance $(1=$ least important to $3=$ most important $)$.

cTotal available votes: 36 for Panel 1, 54 for Panel 2.

of direct interaction among participants and, unlike focus group discussions, addresses one specific and overarching question. We have reported ideas from two sets of key informants regarding how to encourage provider willingness to recommend diaphragm use. Panel 1 achieved agreement about certain things, although subsequent stages of the NGT process did not resolve the importance of all the items elicited. Panel 2, which had more participants and a more homogenous professional composition, produced both more ideas and greater consensus after several voting rounds. Both sets of panellists highlighted that providers and patients need to be better informed about the diaphragm and its specific advantages. Further, panellists appear to be calling for qualified persons to talk about the benefits and advantages of the device. Such detailing is important because currently the diaphragm is little discussed. These insights will guide our future activities. A survey designed to assess barriers and obstacles to diaphragm use, and to refine ideas for intervention design, is being developed from a distillation of the ideas generated during the two NGT meetings.

\section{Study strengths and limitations}

Many variants of the NGT technique have been proposed. The enhancements adopted here closely adhere to the key elements of the basic approach ${ }^{1,2}$ and permit greater efficiency. NGTs can be used for multiple purposes, not only for building consensus. We sought to identify the most important ideas for encouraging diaphragm use and to narrow the pool of responses that were deemed most relevant. The much-reduced final list of responses will be used to guide future research and examined further using survey methods with larger and more generalisable samples. NGT panels comprise a select group of individuals, but our experience suggests that two meetings are necessary and usually sufficient to identify a full array of responses to a particular question and to achieve 'idea saturation'. Typically, the small information increment obtained from a third NGT session does not warrant additional effort and cost. Moreover, group size is a less important concern than its composition. A larger panel need not generate more useful ideas, but having too much heterogeneity may preclude a greater sense of agreement.

\section{Conclusions}

The NGT is a useful, relatively inexpensive participatory technique for collating expert opinion where little evidence exists, without the need for a 'face-to-face' meeting of participants. Although the Delphi method has been used more often in the family planning/reproductive health care field, we contend that the NGT offers greater efficiency when used with the refinements described. This study has presented a practical application of such an enhanced NGT and has reported views of two groups of key informants regarding ideas for promoting provider willingness to recommend diaphragms. Both groups highlighted 
educational needs for providers and patients and the need to facilitate greater method discussion. Ideas rated most highly indicate that to make the diaphragm a more plausible option, both providers and patients should be better informed about the diaphragm and its specific advantages.

Very little is known about specific facilitators to implementing diaphragm interventions. Input is needed from those who will provide interventions and serve as critical gatekeepers to this method. The items generated by the two expert panels are being used to develop questionnaire items and key themes that will be endorsed further for setting priorities on intervention strategies. These strategies will be further validated in our ongoing research.

\section{Statements on funding and competing interests}

Funding This study was funded by the Lister Hill Center of the University of Alabama at Birmingham, AL, USA.

Competing interests None identified.

\section{References}

1 van Teijlingen E, Pitchforth E, Bishop C, Russell E. Delphi method and nominal group technique in family planning and reproductive health research. J Fam Plann Reprod Health Care 2006; 32: 249-252.

2 Delbecq AL, van de Ven AH, Gustafson DH. Group Techniques for Program Planning: A Guide to Nominal Group and Delphi Processes. Glenview, IL: Scott Foresman, 1975.

3 Linstone HA. The Delphi Method: Techniques and Applications. Reading, MA: Addison-Wesley, 1975.

4 Glasier A, Brechin S, Raine R, Penney G. A consensus process to adapt the World Health Organization selected practice recommendations for UK use. Contraception 2003; 68: 327-333.

5 Wang CC, Wang Y, Zhang K, Fang J, Liu W, Luo S, et al. Reproductive health indicators for China's rural areas. Soc Sci Med 2003; 57: 217-225.

6 Jones J, Hunter D. Qualitative research: consensus methods for medical and health services research. BMJ 1995; 311: 376-380.

7 Ferri CP, Prince M, Brayne C, Brodaty H, Fratiglioi L, Ganguli $\mathrm{M}$, et al.; Alzheimer's Disease International. Global prevalence of dementia: a Delphi consensus study. Lancet 2005; 366: 2112-2117.

8 Oranga HM, Nordberg E. The Delphi panel method for generating health information. Health Policy Plan 1993; 8: 405-412.

9 Zeitlin J, Wildman K, Breart G, Alexander S, Barros H, Blondel $\mathrm{B}$, et al. Selecting an indicator set for monitoring and evaluating perinatal health in Europe: criteria, methods and results from the PERISTAT project. Eur J Obstet Gynecol Reprod Biol 2003; 111: S5-S14.

10 Marsden J, Dolan B, Holt L. Nurse practitioner practice and deployment: electronic mail Delphi study. J Adv Nurs 2003; 43: 595-605.

11 Scotland GS, Bullough CHW. What do doctors think their caseload should be to maintain their skills for delivery care? Int J Gynecol Obstet 2004; 87: 301-307.

12 Green B, Jones M, Hughes D, Williams A. Applying the Delphi technique in a study of GPs' information requirements. Health Soc Care Community 1999; 7: 198-205.

13 Williams PL, Webb C. The Delphi technique: a methodological discussion. J Adv Nurs 1994; 19: 180-186.

14 Gallagher M, Bradshaw C, Nattress H. Policy priorities in diabetes care: a Delphi study. Qual Health Care 1996; 5: 3-8.

15 McCourt C, Thomas BG. Evaluation of a problem-based curriculum in midwifery. Midwifery 2001; 17: 323-331.

16 Telford R, Boote JD, Cooper CL. What does it mean to involve consumers successfully in NHS research? A consensus study. Health Expect 2004; 7: 209-220.

17 Frankel, S. NGT + MDS: an adaptation of the nominal group technique for ill-structured problems. J Appl Behav Sci 1997; 33: 543-551.

18 Gallagher M, Hares T, Spencer J, Bradshaw C, Webb I. The nominal group technique: a research tool for general practice? Fam Pract 1993; 10: 76-81.

19 Miller D, Shewchuk R, Elliott TR, Richards S. Nominal group technique: a process for identifying diabetes self-care issues among patients and caregivers. Diabetes Educ 2000; 26: 305-314.

20 Elliott TR, Shewchuk R. Using the nominal group technique to identify problems experienced by persons living with severe physical disability. J Clin Psychol Med Settings 2002; 9: 65-76.
21 Harvey SM. A new look at an old method: the diaphragm. Perspect Sex Reprod Health 2003; 35: 270-273.

22 Bounds W, Guillebaud J, Dominik R, Dalberth BT. The diaphragm with and without spermicide. A randomized, comparative efficacy trial. J Reprod Med 1995; 40: 764-774.

23 Ferreira $A E$, Araujo MJ, Regina $C H$, Diniz SG, Faundes $A$. Effectiveness of the diaphragm, used continuously without spermicide. Contraception 1993; 48: 29-35.

24 Trussell J, Strickler J, Vaughan B. Contraceptive efficacy of the diaphragm, the sponge and the cervical cap. Fam Plann Perspect 1993; 25: 100-105, 135.

25 Moench T, Chiapto T, Padian N. Preventing disease by protecting the cervix: the unexplored promise of internal vaginal barrier devices. AIDS 2001; 15: 1595-1602.

26 Minnis AM, Padian NS. Effectiveness of female controlled barrier methods in preventing sexually transmitted infections and HIV: current evidence and future research directions. Sex Transm Infect 2005: 81: 193-200.

27 Balzarini J, Van Damme L. Microbicide drug candidates to prevent HIV infection. Lancet 2007; 369: 787-797.

28 Padian NS, van der Straten A, Ramjee G, Chipato T, de Bruyn G, Blanchard K, et al.; MIRA Team. Diaphragm and lubricant gel for prevention of HIV acquisition in southern African women: a randomised control trial. Lancet, 2007; 370: 251-261.

29 Ortayli N, Bulut A, Nalbant H, Cottingham J. Is the diaphragm a viable option for women in Turkey? Int Fam Plann Perspect 2000; 26: 36-42.

30 Bulut A, Ortayli N, Ringheim K, Cottingham J, Farley TMM, Peregoudov $\mathrm{A}$, et al. Assessing the acceptability, service delivery requirements, and use effectiveness of the diaphragm in Colombia, Philippines, and Turkey. Contraception 2001; 63 267-275.

31 Centers for Disease Control and Prevention. Sexually Transmitted Disease Surveillance 2006. Atlanta: Division of STD Prevention, National Center for HIV/AIDS, Viral Hepatitis, STD, and TB Prevention, 2007. http://www.cdc.gov/STD/ STATS/pdf/Surv2006.pdf [Accessed 6 August 2008].

32 Willis GB. Cognitive Interviewing: A Tool for Improving Questionnaire Design. Thousand Oaks, CA: Sage Publications, 2005.

33 Sudman S, Bradburn NM, Schwartz N. Thinking About Answers. The Application of Cognitive Processes to Survey Methodology. San Francisco, CA: Jossey Bass, 1996.

\section{New Clinical 篗 Effectiveness Unit}

The Clinical Effectiveness Unit (CEU) of the Faculty of Sexual \& Reproductive Healthcare moved to Glasgow on 1 September 2008.

The new CEU team is based in Sandyford sexual health clinic, hosted by Greater Glasgow \& Clyde Health Board.

The Members' Enquiry Service will continue to operate and should be accessed via the Clinical Enquiries section on the Faculty website (www.fsrh.org).

\section{Director of CEU: Dr Louise Melvin Researcher: Julie Craik Administrator/PA: Janice Paterson}

Clinical Effectiveness Unit, Sandyford, 2/6 Sandyford Place, Glasgow G3 7NB, UK. Tel: 0141232 8459. Fax: 01412328448. E-mail: ceu.members@ggc.scot.nhs.uk 